\title{
Candida Coinfection among Patients with Pulmonary tuberculosis in the World; A Systematic Review and Meta- analysis of Cross-Sectional Studies
}

Mehran Ghazalibina

Tehran University of Medical Sciences

Ali Shakerimoghaddam

kashan uni med sci

Azad Khaledi ( $\nabla$ azadkh99@gmail.com)

Kashan Uni Med Sci https://orcid.org/0000-0003-3015-7490

Research article

Keywords: Meta-Analysis, Pulmonary tuberculosis, Coinfection, Candida

Posted Date: September 23rd, 2019

DOI: https://doi.org/10.21203/rs.2.14804/v1

License: (c) (i) This work is licensed under a Creative Commons Attribution 4.0 International License. Read Full License 


\section{Abstract}

Background Diagnosis of fungal co-infections in patients with pulmonary tuberculosis has critical importance. In this review, we aimed to determine the prevalence of candida coinfection in patients with pulmonary tuberculosis.Methods The present systematic review of cross-sectional studies was conducted based on the Preferred Reporting Items for Systematic reviews and Meta-analysis (PRISMA) Protocol. Studies published online in English from January 2001 to March 2019 were assessed. Literature search was performed in Web of Science, MEDLINE/PubMed, and Scopus databases using keywords combinations of "pulmonary fungal", "pulmonary coinfection", OR "pulmonary mycosis", "pulmonary fungal infections/agents", OR "polymicrobial infection", OR "secondary infection", OR "mixed infections", "pulmonary candidiasis", "fungi coinfection", "fungal co-colonization", AND "pulmonary tuberculosis", OR "pulmonary TB". Data was analyzed using Comprehensive Meta-Analysis software. Heterogeneity between studies was evaluated by Cochran's Q, and I 2 tests. Results The pooled global prevalence of candida coinfection among patients with pulmonary tuberculosis was $25.7 \%$ (95\% Cl: 23.7-27.9). C. albicans was the most prevalent Candida spp. with a pooled prevalence of $65.8 \%$ (95\% Cl: 54.3-75.7). Risk factors of candida coinfection included smoking, diabetes, advanced age, and low body mass index.Conclusion The present review showed the high rate of candida coinfection among patients suffering from pulmonary tuberculosis. Adequate measures are necessary to early diagnose and treat these infections.

\section{Background}

Fungal co-infections are of critical importance in individuals receiving antibiotics and/or corticosteroids due to immunodeficiency disorders such as AIDS or severe pulmonary diseases such as tuberculosis [1]. Undiagnosed opportunistic fungal infections may even lead to death; particularly in patients with compromised immune system [2]. Patients with tuberculosis are immunocompromised and susceptible to fungal and lungs mycotic infections [3].

Generally, up to 1 million people recovered from tuberculosis develop concomitant fungal infections annually which are often misdiagnosed as relapsed TB [4]. Pulmonary tuberculosis is caused by Mycobacterium tuberculosis currently affecting about $1 / 3$ of human populations [5]. Furthermore, two million people die from TB complications annually [6].

Depending on the population studied and methods used for isolating fungi, candida species have been identified in 3 to $84 \%$ of sputum specimens. The prevalence of candida coinfection has been reported in $15-32 \%$ of patients with pulmonary tuberculosis [1].

The main risk factors of primary and secondary fungal pulmonary coinfection in TB patients include immunodeficiency due to mucosal or cutaneous barrier disruption, using broad-spectrum antibiotics and steroids, premature birth, hemodialysis, cytotoxic chemotherapy, tissue transplantation, chronic diseases, neutropenia, defects in the function of innate or cell-mediated immunity, metabolic syndrome, solid and hematologic malignancies, advanced age , recent radiation therapy, burns, prolonged hospitalization, severe trauma, bacterial infections, recent surgery, and implanted central intravascular access devices [7]

Unspecific clinical manifestations deter the diagnosis of fungal pulmonary co-infections imposing patients with tuberculosis at high risk of morbidity and mortality [8]. In particular, fungal infections caused by candida render relatively higher rates of morbidity and mortality [9]. Infections caused by fungi are responsible for death of about 1.5 million people annually. More than $90 \%$ of all fungal-associated deaths are caused by four main genera including Cryptococcus, Candida, Aspergillus, and Pneumocystis [10].

Candida albicans is a potentially pathogenic fungi causing very mild to severe invasive mucocutaneous infections, particularly in immunocompromised individuals [11]. Candida species comprise the fourth main causes of nosocomial bloodstream infections (BSI) and are responsible for $8 \%$ to $10 \%$ of all hospital acquired BSIs in the United States [12]. Therefore, it is important to focus on co-infections of these saprophytic organisms, especially in patients with pulmonary tuberculosis [13].

Recently, the incidence of infections caused by non-albicans Candida spp has increased [4]. Most of these organisms show resistance to routine antifungal drugs [14]. On the other hand, accurate identification of candida species is necessary to appropriately select antifungal agents and treat invasive candidiasis [15]. Concerning the significance of concurrent candidiasis in 
patients with tuberculosis and the lack of a comprehensive review on this issue, the present systematic review and meta-analysis aimed to determine the prevalence of candidiasis caused by different candida species in patients with pulmonary tuberculosis.

\section{Methods}

\section{Search strategy}

The present systematic review of cross-sectional studies was conducted based on the Preferred Reporting Items for Systematic reviews and Meta-analysis (PRISMA) Protocol (File1). A systematic literature search was conducted in Web of Science, MEDLINE/PubMed, Scopus, Google Scholar, Cochrane Library, and Science Direct databases. Studies published between January 2001 and March 2019 was collected. Medical subject headings (MeSH) and non-MeSH keywords were searched within titles, abstracts or keywords: Search strategy was as "pulmonary fungal", "pulmonary coinfection", OR "Pulmonary mycosis", "pulmonary fungal infections/agents", OR "Polymicrobial infection", OR "Secondary infection", OR "Mixed infections", "pulmonary Candidiasis", "fungi coinfection”, "Fungal co-colonization”, AND "pulmonary tuberculosis", OR "pulmonary TB". Only studies published in English were included. The literature search was conducted by A.K and A.S. Reference lists of recruited studies were checked to find additional relevant articles.

\section{Inclusion and exclusion criteria}

Titles, abstracts, and full texts of articles were read to find relevant studies and check eligibility criteria. Inclusion criteria were a) cross-sectional design; and b) assessing coinfection of candidiasis and pulmonary tuberculosis. Studies published before 2001, case reports, meeting reports, letters to editors, abstracts, case series, congress articles, editorials, literatures reporting inadequate data, articles published in languages other than English, duplicate publications, and narrative or meta-analysis/systematic reviews were excluded. Two reviewers (AK, AS) independently assessed the studies based on the inclusion and exclusion criteria. Disagreements on the inclusion or exclusion of studies were resolved by discussions between the two reviewers or by involving a third researcher.

\section{Quality evaluation}

Appraisal tool for Cross-Sectional Studies (AXIS) was used for assessing the quality of the included studies. Using this check, twenty items were evaluated in each study. If the related data was documented, a question was scored 'yes'. In case of any doubt or indistinct data, a question was marked 'no' or 'can't tell'. According to the scoring system and the number of questions scored 'yes', the quality of studies was finally categorized as either 'strong', 'intermediate', or 'weak' [16]. Studies with weak quality were excluded (File 2).

\section{Data extraction}

The following data was extracted and tabulated: first author's name, year of publication, location (country), sample size $\left(\mathrm{TB}^{+}\right)$, rate of candida coinfection, and detection method.

\section{Statistical analysis}

We used Comprehensive Meta-Analysis software (Version 3.3.070) for meta-analysis. Statistical significance level was considered as $P<0.05$. Random effects model was used to calculate overall effects. Sources of between-study heterogeneity were assessed

using Cochran's $Q$ and I square $(R)$ tests and subgroup analysis. Egger's regression asymmetry test was used to detect publication bias. The correlations between pulmonary candidiasis coinfection and patients' characteristics such as age, gender, body mass index (BMI), and factors such as alcohol consumption, smoking, and diabetes mellitus (DM) were also scrutinized by Spearman correlation.

\section{Results}

\section{Study selection}


In total, 984 records were identified in primary literature search (Figure1). Of these, 453 duplicates were removed. Then abstracts and titles of 533 remained records were screened which resulted in exclusion of 401 irrelevant articles. Next, 130 full-text articles were assessed for eligibility criteria which led to the exclusion of 105 additional studies that did not fulfill inclusion criteria. After that, 25 studies were selected for qualitative appraisal. From these, seven studies with weak qualities were excluded. Finally, 18 studies entered quantitative synthesis (Meta-analysis).

\section{Features of the selected studies}

All the 18 included cross-sectional studies had been published between January 2001 and March 2019. The studies were from countries in Asia and Africa, especially from India with 9 reports. No report was from developed countries. Overall, 2139 TB positive patients were analyzed. The rate of candidiasis coinfection varied from $2.8 \%$ to $55 \%$. Only phenotypic methods (i.e. AFB analysis-Direct Microscopy-Culture, Gram staining, $\mathrm{KOH}$ Mount, Ziehl-Neelsen technique, CHROM agar Candida culture method, Sugar fermentation tests, and Germ tube test) had been used to detect tuberculosis and fungal infections in all the studies. The studies' characteristics have been described in Table 1

\section{Overall effects}

The pooled global prevalence of candidiasis coinfection among patients with pulmonary tuberculosis was $25.7 \%$ (95\% Cl: $23.7-$ 27.9, Q=177.5, $Z=18.7$ ) (Table 2 and Figure 2). The combined frequencies of candidiasis coinfections were 27.9\% (95\% Cl: 21-36, $\mathrm{Q}=44, \mathrm{Z}=4.9), 9.7 \%(95 \% \mathrm{Cl}: 1.3-46.8, \mathrm{Q}=51, \mathrm{Z}=2)$, and $30.7 \%$ (95\% Cl: 23.2-39.5, Q=4.6, Z=4.1) in India, Iran, and Nigeria respectively. . No publication bias was detected by Funnel plot (Figure 3) and Egger's linear regression $(P=0.37)$.

According to subgroup analysis, $C$. albicans was the most prevalent Candida spp. coinfected patients with pulmonary tuberculosis worldwide $(65.8 \%, 95 \% \mathrm{Cl}: 54.3-75.7, \mathrm{Q}=47.6, \mathrm{Z}=2.6)$. Also, the combined frequencies of $C$. tropicalis and $C$. parapsilosis were $16.9 \%$ (95\% Cl: 10.2-26.8), and 14.3\% (95\% Cl: 7.1-26.7), respectively (Table 3).

\section{Risk factors of candidiasis coinfection and its correlation with patients' demographic characteristics}

A significant correlation was reported between advanced age and candidiasis coinfection in two studies $(p<0.05$, Table 4). Also, three studies reported a significant correlation between male gender and candidiasis coinfection whereas only one study showed a correlation with female gender $(p<0.05)$. Alcohol consumption was not associated with candidiasis coinfection in neither of the studies $(\mathrm{p}>0.05)$. One study reported low BMI as a potential risk factor for pulmonary candida coinfection, and two another studies described a correlation between candidiasis coinfection and smoking $(p<0.05)$. Finally, two studies reported higher prevalence of pulmonary fungal coinfection in tuberculosis patients with diabetes mellitus $(p<0.05)$.

\section{Discussion}

The global rate of candidiasis coinfection varies from $2.8 \%$ to $55 \%$ in patients with pulmonary tuberculosis. The present systematic review showed a combined global prevalence of $25.7 \%$ for candidiasis coinfection in patients with pulmonary tuberculosis. The pooled frequencies of candidiasis coinfections were $27.9 \%, 9.7 \%$, and $30.7 \%$ in India, Iran, and Nigeria respectively. The pooled prevalence of candida coinfection was also obtained as $45.5 \%$ in Cameroon. Nevertheless, as estimations in Cameroon, Iraq, and Kenya were based on only one study, the reported frequencies may not indicate the true incidence of candidiasis coinfection in these countries. Therefore, it is recommended to perform more studies on this issue in the mentioned regions to more accurately estimate the rate of coinfection. Variations in the frequency of candidiasis and pulmonary tuberculosis coinfection probably reflect the differences in the local prevalence of different candida species secondary to different environmental conditions. Also, the types of clinical samples and detection methods can affect the reported rate of the coinfection [2].

Several studies have described candida species as the most common fungal agents retrieved from sputum of patients with pulmonary tuberculosis. Nonetheless, because of the presence of these fungi in throats of $30 \%$ of healthy individuals and risk of cross-contamination during sputum collection, the importance of candidiasis in tuberculosis patients has been undermined [17]. Kahanpaa et al. showed that C. albicans was the most common organism recovered from $60-70 \%$ of sputum samples, $16.5 \%$ of

Page $4 / 12$ 
bronchial secretions, and $20.4 \%$ of lung fragments. C. albicans has also been isolated from $53.0 \%$ of healthy subjects' oral samples [18].

Similarly, $C$. albicans comprised the most prevalent fungus coinfected patients with pulmonary tuberculosis followed by $C$. tropicalis and C. parapsilosis with respective frequencies of $65.8 \%, 16.9 \%$, and $14.3 \%$. In fact, all the studies included in present review reported $C$. albicans as the most common cause of fungal-tuberculosis coinfection. In line with our results, $C$. tropicalis has been noted as the second most prevalent cause of fungal coinfection in patients with tuberculosis. $C$. tropicalis is a new opportunistic pathogen representing higher rates of severe disease and deep tissue invasion than $C$. albicans in immunocompromised hosts $[19,20]$. According to our findings and results obtained by other studies, the high rate of coinfection with $C$. albicans and other Candida spp. may be due to cross-contamination or co-colonization and not necessarily reflect actual infection. For obviating this problem, it is recommended to use bronchoscopy rather than sputum sampling to reduce the risk of cross-contamination of samples with upper respiratory secretions. In practice; however, bronchoscopy is not always used in developing countries such as India and Cameroon [21].

Because of insufficient clinical data and unavailability of radiologic images, a high ratio of pulmonary fungal and tuberculosis coinfections reported in the analyzed studies may merely indicate colonization rather than actual infections. Nevertheless, clinical and radiological studies alone are inadequate to differentiate pulmonary fungal from tuberculosis infections. Therefore, it is necessary to screen primary/secondary fungal infections using accurate detecting methods in patients with pulmonary tuberculosis [22]. This is of crucial importance considering that co-infections with opportunistic fungal and other non-tuberculosis pathogens can aggravate the clinical course of tuberculosis, accelerate disease recurrence, and increase mortality rate [10]. Nevertheless, no comprehensive epidemiological data is available about fungal coinfection as they frequently remain either misdiagnosed or undiagnosed. Except for Coccidioidomycosis, no fungal diseases have actually been reported to the Centers for Disease Control and Prevention $(C D C)[10]$.

In the present review, three studies $[3,23,24]$ showed a significant correlation between male gender and candidiasis coinfection $(p<0.05)$. On the other hand, only one study[25] showed a correlation between female gender and candidiasis coinfection $(p<0.05)$. Our findings agreed with the reports of WHO indicating male gender as a predisposing factor for tuberculosis infection [26]. This may possibly be related to higher environmental exposure of males than females to bacterial and fungal infections [27]. Nonetheless, Hidalgo et al. reported equal rates of Candida spp. colonization in both males and females [28]. Altogether, it is highly recommended to accurately identify all organisms recovered from clinical samples of patients with tuberculosis. The limitation of this study is that we only cite studies that existed in databases and other studies that were unpublished were not included in the study. We also did not contact to the authors of the articles in cases where further clarification was required.

\section{Conclusion}

The present review revealed high rate of candidiasis coinfection among patients with pulmonary tuberculosis. Considering that clinical and radiological evidences of fungal coinfections are unclear; accurate diagnostic procedures should be conducted to early diagnose and treat these opportunistic infections and decrease mortality and morbidity rates associated with fungal coinfection in tuberculosis patients.

\section{Abbreviations}

PRISMA: Preferred Reporting Items for Systematic reviews and Meta-analysis, BSI: bloodstream infections, AXIS: Appraisal tool for Cross-Sectional Studies, BMI: body mass index, DM: diabetes mellitus. .

\section{Declarations}

\section{Funding support}

This study did not receive any financial support. 


\section{Acknowledgement}

We would like to thanks our friends for their help in the present study.

\section{Author's contributions}

AK conducted data extraction, analysis, and wrote the first draft of the paper. AM conducted data extraction, design of the study, analyses, and drafting of the article. All authors contributed to discussion of results and writing of the manuscript.

\section{Funding}

Not applicable.

\section{Availability of data and materials}

All data used and analyzed during this study is based on an original article and is available from the corresponding author, by request.

\section{Ethics approval and consent to participate}

Not applicable.

\section{Consent for publication}

Not applicable

\section{Competing interests}

The authors declare that they have no competing interests

\section{References}

1. Fontalvo DM, Jiménez Borré G, Gómez Camargo D, Chalavé Jiménez N, Bellido Rodríguez J, Cuadrado Cano B, et al.Tuberculosis and fungal co-infection present in a previously healthy patient. Colombia Médica. 2016; 2:105-8.

2. Baradkar V, Mathur M, Wanjari K, Kumar S.Candida in pulmonary tuberculosis. Bombay Hospital Journal. 2009:52-3.

3. Amiri MRJ, Siami R, Khaledi A.Tuberculosis Status and Coinfection of Pulmonary Fungal Infections in Patients Referred to Reference Laboratory of Health Centers Ghaemshahr City during 2007-2017. Ethiopian journal of health sciences. 2018; 6.

4. Naz SA, Tariq P.A study of the trend in prevalence of opportunistic Candidal coinfections among patients of pulmonary tuberculosis. Pak J Bot. 2004:857-62.

5. sani Tavanaee A, Ashna H, Kaffash A, Khaledi A, Ghazvini K.Mutations of rpob Gene Associated with Rifampin Resistance among Mycobacterium Tuberculosis Isolated in Tuberculosis Regional Reference Laboratory in Northeast of Iran during 2015-2016. Ethiopian Journal of Health Sciences. 2018; 3:299-304.

6. Suliman S, Thompson EG, Sutherland J, Weiner 3rd J, Ota MO, Shankar S, et al.Four-gene pan-African blood signature predicts progression to tuberculosis. American journal of respiratory and critical care medicine. 2018; 9:1198-208.

7. Osman NM, Gomaa AA, Sayed NM.Microarray detection of fungal infection in pulmonary tuberculosis. Egyptian Journal of Chest Diseases and Tuberculosis. 2013; 1:151-7.

8. Pfaller M, Diekema D.Epidemiology of invasive candidiasis: a persistent public health problem. Clinical microbiology reviews. 2007; 1:133-63.

9. Flückiger U, Marchetti O, Bille J, Eggimann P, Zimmerli S, Imhof A, et al.Treatment options of invasive fungal infections in adults. Swiss medical weekly. 2006; 29-30:447-63.

10. Brown GD, Denning DW, Gow NA, Levitz SM, Netea MG, White TC.Hidden killers: human fungal infections. Science translational medicine. 2012; 165:165rv13-rv13. 
11. Chong S, Lee KS, Chin AY, Chung MJ, Kim TS, Han J.Pulmonary fungal infection: imaging findings in immunocompetent and immunocompromised patients. European journal of radiology. 2006; 3:371-83.

12. Wisplinghoff $H$, Bischoff $T$, Tallent SM, Seifert H, Wenzel RP, Edmond MB.Nosocomial bloodstream infections in US hospitals: analysis of 24,179 cases from a prospective nationwide surveillance study. Clinical infectious diseases. 2004; 3:309-17.

13. Mathavi S, Shankar R, Kavitha A, Sasikala G, Priyadharsini I.A study on prevalence of pulmonary candidiasis among tuberculosis patients and use of chromagar in identification of Candida species. Journal of Drug Delivery and Therapeutics. 2014; 3:118-21.

14. Latha R, Sasikala R, Muruganandam N, Venkatesh Babu R.Study on the shifting patterns of Non Candida albicans Candida in lower respiratory tract infections and evaluation of the CHROMagar in identification of the Candida species. J Microbiol Biotech Res. 2011; 3:113-9.

15. Feller L, Anagnostopoulos C, Bouckaert M, Raubenheimer E.HIV/TB co-infection: literature review and report of multiple tuberculosis oral ulcers. SADJ: journal of the South African Dental Association=tydskrif van die Suid-Afrikaanse Tandheelkundige Vereniging. 2005; 8:330-2, 43.

16. Downes MJ, Brennan ML, Williams HC, Dean RS.Development of a critical appraisal tool to assess the quality of crosssectional studies (AXIS). BMJ open. 2016; 12:e011458.

17. Santiwongkarn P, Kachonboon S, Thanyasrisung P, Matangkasombut O.Prevalence of oral Candida carriage in Thai adolescents. Journal of investigative and clinical dentistry. 2012; 1:51-5.

18. Kahanpää A.Bronchopulmonary occurrence of fungi in adults especially according to cultivation material. Acta Pathologica et Microbiologica Scandinavica. 1972; 227.

19. Chen J, Chen J, Lane S, Liu H.A conserved mitogen-activated protein kinase pathway is required for mating in Candida albicans. Molecular microbiology. 2002; 5:1335-44.

20. Roilides E, Farmaki E, Evdoridou J, Francesconi A, Kasai M, Filioti J, et al.Candida tropicalis in a neonatal intensive care unit: epidemiologic and molecular analysis of an outbreak of infection with an uncommon neonatal pathogen. Journal of clinical microbiology. 2003; 2:735-41.

21. El-Ebiary M, Torres A, Fabregas N, de la BELLACASA JP, Gonzalez J, Ramirez J, et al.Significance of the isolation of Candida species from respiratory samples in critically ill, non-neutropenic patients: an immediate postmortem histologic study. American journal of respiratory and critical care medicine. 1997; 2:583-90.

22. Machida M, Gomi K. Aspergillus: molecular biology and genomics: Horizon Scientific Press; 2010.

23. Namratha W. Nandihal RBaAD.Prevalence of Different Species of Candida in Sputum of Pulmonary Tuberculosis. International Journal of Current Microbiology and Applied Sciences. 2018; 9:3072-5.

24. Suad Yousuf Aldorkee MFAj.Prevalence of Opportunistic Fungal Infection in Pulmonary Tuberculous Patients. Journal of Babylon University/Pure and Applied Sciences. 2017; 3.

25. Kali A, Charles MP, Noyal MJ, Sivaraman U, Kumar S, Easow JM.Prevalence of Candida co-infection in patients with pulmonary tuberculosis. The Australasian medical journal. 2013; 8:387.

26. Organization WH. Global tuberculosis report 2013: World Health Organization; 2013.

27. Ndukwu C, Mbakwem-Aniebo C, Frank-Peterside N.Prevalence of Candida Co-Infections among Patients with Pulmonary Tuberculosis in Emuoha, Rivers State, Nigeria. IOSR Journal of Pharmacy and Biological Sciences. 2016; 5:60-3.

28. Franquet T, Giménez A, Hidalgo A.Imaging of opportunistic fungal infections in immunocompromised patient. European journal of radiology. 2004; 2:130-8.

29. Rathod VS, Raut JS, Mohan Karuppayil S.Antifungal drug susceptibility of Candida albicans isolates from pulmonary tuberculosis patients. Int J Pharm Pharm Sci. 2012; Suppl 5:323-6.

30. Mwaura E, Matiru V, Bii C. Mycological Findings of Sputum Samples from Pulmonary Tuberculosis Patients Attending TB Clinic in Nairobi, Kenya. Virol Mycol 2: 119. doi: 10.4172/2161-0517.1000 119 Page 2 of 6 threatening diseases [12]. Candida; 2013.

31. Yahaya H, Taura D, Gwarzo M, Ibrahim A, Ali B, Muhammad A.Diversity of Respiratory Yeasts from Suspected Pulmonary Tuberculosis Patients. Scholars Journal of Applied Medical Sciences. 2014:3145-50. 
32. Jabbari MR, Shokohi T, Abastabar M, Aghili SR, Aliyali M, Mohammadi G, et al.Coexistence of opportunistic mycosis and mycobacterium tuberculosis in patients attending the Central Tuberculosis Reference Laboratory of Ghaemshahr city, Iran. International Journal of Mycobacteriology. 2015:129.

33. Nawange M, Kavishwar A.Prevalence of opportunistic fungal infection in patients with pulmonary tuberculosis in Madhya Pradesh, Central India. J Microbiol Biomed Res. 2015:6.

34. Njunda AL, Nsagha DS, Assob JCN, Abange BW, Tamoh AJ, Kwenti TE.Pulmonary Paragonimiasis and Aspergillosis in Patients Suspected of Tuberculosis in Yaounde, Cameroon. British Microbiology Research Journal. $2015 ; 4$.

35. Aghili SR, Shokohi T, Hedayati MT, Abastabar M, Aliyali M, Hasanpour H.Invasive forms of Candida and Aspergillus in sputum samples of pulmonary tuberculosis patients attending the tuberculosis reference laboratory in Ghaemshahr, Northern Iran: An analysis of samples collected during the past 10 years. International journal of mycobacteriology. 2016:S179-S80.

36. Babita SS, Prabhat K.Prevalence of mycotic flora with pulmonary tuberculosis patient in a tertiary care hospital. Int J Contemporary Med Res. 2016; 9:2563-4.

37. Astekar M, Bhatiya PS, Sowmya G.Prevalence and characterization of opportunistic candidal infections among patients with pulmonary tuberculosis. Journal of oral and maxillofacial pathology: JOMFP. 2016; 2:183.

38. Hanson A, Enoch AS, Wokem GN.Tuberculosis-Candida Co-Infection in Patients having Pulmonary Tuberculosis Attending DOTs Clinic in Rumuigbo Model Primary Health Centre in Port Harcourt, Nigeria. International Journal of TROPICAL DISEASE \& Health. 2019:1-7.

39. Najeeb MAB, Mahantesh BN.Prevalence of Fungi as Opportunistic Pathogens in Active and Post-Treated Pulmonary Tuberculosis Cases-A Comparative Study. EC Microbiology. 2019:153-7.

\section{Tables}

Table 1. Characteristics of studies included in the present review

\begin{tabular}{|c|c|c|c|c|c|c|c|}
\hline \multirow[t]{2}{*}{ Author } & \multirow[t]{2}{*}{ Time of Study } & \multirow[t]{2}{*}{ Publication(Year) } & \multirow[t]{2}{*}{ Location(Country) } & \multirow[t]{2}{*}{ Sample Size(TB+) } & \multirow[t]{2}{*}{ Candida- Coinfection } & \multicolumn{2}{|c|}{ Detection Method } \\
\hline & & & & & & Molecular & Phenotypic $^{1}$ \\
\hline Baradkar[ 2 ] & $2006-2007$ & 2009 & India & 100 & 26 & - & + \\
\hline Rathod[ 29 ] & $2007-2008$ & 2012 & India & 100 & 18 & - & + \\
\hline Kali[ 25 ] & $2010-2011$ & 2013 & India & 75 & 30 & - & + \\
\hline Mwaura[ 30 ] & 2009 & 2013 & Kenya & 172 & 42 & - & + \\
\hline Mathavi[ 13 ] & 2013 & 2014 & India & 107 & 21 & - & + \\
\hline Yahaya[ 31 ] & 2013-2014 & 2014 & Nigeria & 28 & 11 & - & + \\
\hline Jabbari [ 32 ] & 2014 & 2015 & Iran & 25 & 12 & - & + \\
\hline Yadu[ 33 ] & $2006-2007$ & 2015 & India & 100 & 30 & - & + \\
\hline Njunda[ 34 ] & 2014 & 2015 & Cameroon & 44 & 20 & - & + \\
\hline Jabbari [ 35 ] & $2006-2016$ & 2016 & Iran & 430 & 12 & - & + \\
\hline Ndukwu[ 27 ] & - & 2016 & Nigeria & 300 & 76 & - & + \\
\hline Babita[ 36 ] & $2011-2012$ & 2016 & India & 75 & 8 & - & + \\
\hline Astekar[ 37 ] & - & 2016 & India & 60 & 33 & - & + \\
\hline Aldorkee[ 24 ] & $2012-2014$ & 2017 & Iraq & 100 & 8 & - & + \\
\hline Jabbari [ 3 ] & $2007-2017$ & 2018 & Iran & 130 & 6 & - & + \\
\hline Nandihal[ 23 ] & 2012 & 2018 & India & 100 & 32 & - & + \\
\hline Hanson[ 38 ] & - & 2019 & Nigeria & 93 & 32 & - & + \\
\hline ] 39 [Bin Najeeb & 2015 & 2019 & India & 100 & 29 & - & + \\
\hline
\end{tabular}

Table 2. Pooled coinfection of Candida in pulmonary TB patients based on country 


\begin{tabular}{lccccccccc}
\hline Subgroups & \multirow{2}{*}{ Number of studies } & \multicolumn{3}{c}{ Heterogeneity test } & \multicolumn{3}{c}{ Egger's test } & \multicolumn{3}{c}{ Random model } \\
\cline { 2 - 9 } & & $\begin{array}{l}\text { Prevalence } \\
\text { (95\% CI) (\%) }\end{array}$ & $\mathbf{Z}$ & $\mathbf{P}$ & $\mathbf{Q}$ & $\mathbf{P}$ & $\mathbf{I}^{2}$ & $\mathrm{~T}$ & $\mathbf{P}$ \\
\hline Coinfection & 18 & $25.7(23.7-27.9)$ & 18.7 & 0.00 & 177.5 & 0.00 & 90.4 & 0.91 & 0.37 \\
\hline India & 9 & $27.9(21-36)$ & 4.9 & 0.00 & 44 & 0.00 & 81.8 & 1.2 & 0.25 \\
\hline Iran & 3 & $9.7(1.3-46.8)$ & 2 & 0.00 & 51 & 0.00 & 96 & 0.7 & 0.57 \\
\hline Cameroon & 1 & $45.5(31.5-60.1)$ & 0.6 & 0.54 & 0.00 & 1 & 0.00 & - & - \\
\hline Nigeria & 3 & $30.7(23.2-39.5)$ & 4.1 & 0.00 & 4.6 & 0.00 & 56.7 & 2.4 & 0.24 \\
\hline Kenya & 1 & $24.4(18.6-31.4)$ & 6.3 & 0.00 & 0.00 & 1 & 0.00 & - & - \\
\hline Iraq & 1 & $8(4.1-15.2)$ & 6.6 & 0.00 & 0.00 & 1 & 0.00 & - & - \\
\hline
\end{tabular}

Table 3. Sub-groups analysis of Candida species

\begin{tabular}{|c|c|c|c|c|c|c|c|c|c|}
\hline \multicolumn{10}{|c|}{ Candida species } \\
\hline \multirow[t]{2}{*}{ Overall effects } & \multirow[t]{2}{*}{ Number of studies } & \multicolumn{3}{|c|}{ Heterogeneity test } & \multicolumn{3}{|c|}{ Egger's test } & \multicolumn{2}{|c|}{ Random model } \\
\hline & & $\begin{array}{l}\text { Prevalence } \\
(95 \% \text { CI) (\%) }\end{array}$ & Z & $\mathrm{P}$ & $\mathrm{Q}$ & $\mathrm{P}$ & $\mathrm{I}^{2}$ & $\mathrm{~T}$ & $\mathrm{P}$ \\
\hline C. albicans & 15 & $65.8(54.3-75.7)$ & 2.6 & 0.008 & 47.6 & 0.00 & 70.6 & 2.8 & 0.01 \\
\hline India & 8 & $63.7(46.3-78.1)$ & 1.53 & 0.21 & 27.2 & 0.00 & 74.3 & 3.7 & 0.009 \\
\hline Nigeria & 2 & $57.4(47.9-66.4)$ & 1.5 & 0.12 & 0.48 & 0.48 & 0.00 & - & - \\
\hline Iran & 2 & $55.8(32.1-77)$ & 0.46 & 0.84 & 1.7 & 0.19 & 41.4 & & - \\
\hline C. tropicalis & 8 & $16.9(10.2-26.8)$ & 5.3 & 0.00 & 20.5 & 0.005 & 65.8 & 6 & 0.00 \\
\hline India & 5 & $15.6(7.6-29.4)$ & 4 & 0.00 & 10.1 & 0.003 & 60.5 & 5.6 & 0.01 \\
\hline Nigeria & 2 & $24.8(11.4-45.7)$ & 2.3 & 0.02 & 3.1 & 0.07 & 68.6 & - & - \\
\hline C. parapsilosis & 7 & $14.3(7.1-26.7)$ & 4.5 & 0.00 & 19.5 & 0.003 & 69.3 & 5 & 0.003 \\
\hline India & 6 & $15.3(7.1-29.9)$ & 3.8 & 0.00 & 17.3 & 0.004 & 71.1 & 4.7 & 0.009 \\
\hline C. glabrata & 4 & $7.3(2.3-20.7)$ & 1 & 0.00 & 6.3 & 0.09 & 53.1 & 10.4 & 0.009 \\
\hline India & 4 & $7.3(2.3-20.7)$ & 4.1 & 0.00 & 6.3 & 0.09 & 53.1 & 10.4 & 0.009 \\
\hline C. krusei & 5 & $13.8(8.5-21.8)$ & 6.5 & 0.00 & 3.8 & 0.42 & 0.00 & 2.4 & 0.09 \\
\hline India & 3 & $13.9(7.9-24.8)$ & 4.9 & 0.00 & 3.7 & 0.15 & 46.3 & 14.4 & 0.04 \\
\hline C. dubliniensis & 3 & $6.2(2.8-13.1)$ & 6.4 & 0.00 & 0.48 & 0.71 & 0.00 & 10.3 & 0.06 \\
\hline C. guilliermondii & 2 & $4.9(1.6-14.1)$ & 4.9 & 0.00 & 0.72 & 0.39 & 0.00 & - & - \\
\hline
\end{tabular}

Table 4. The correlation between pulmonary candida coinfection with characteristics of patients and risk factors 


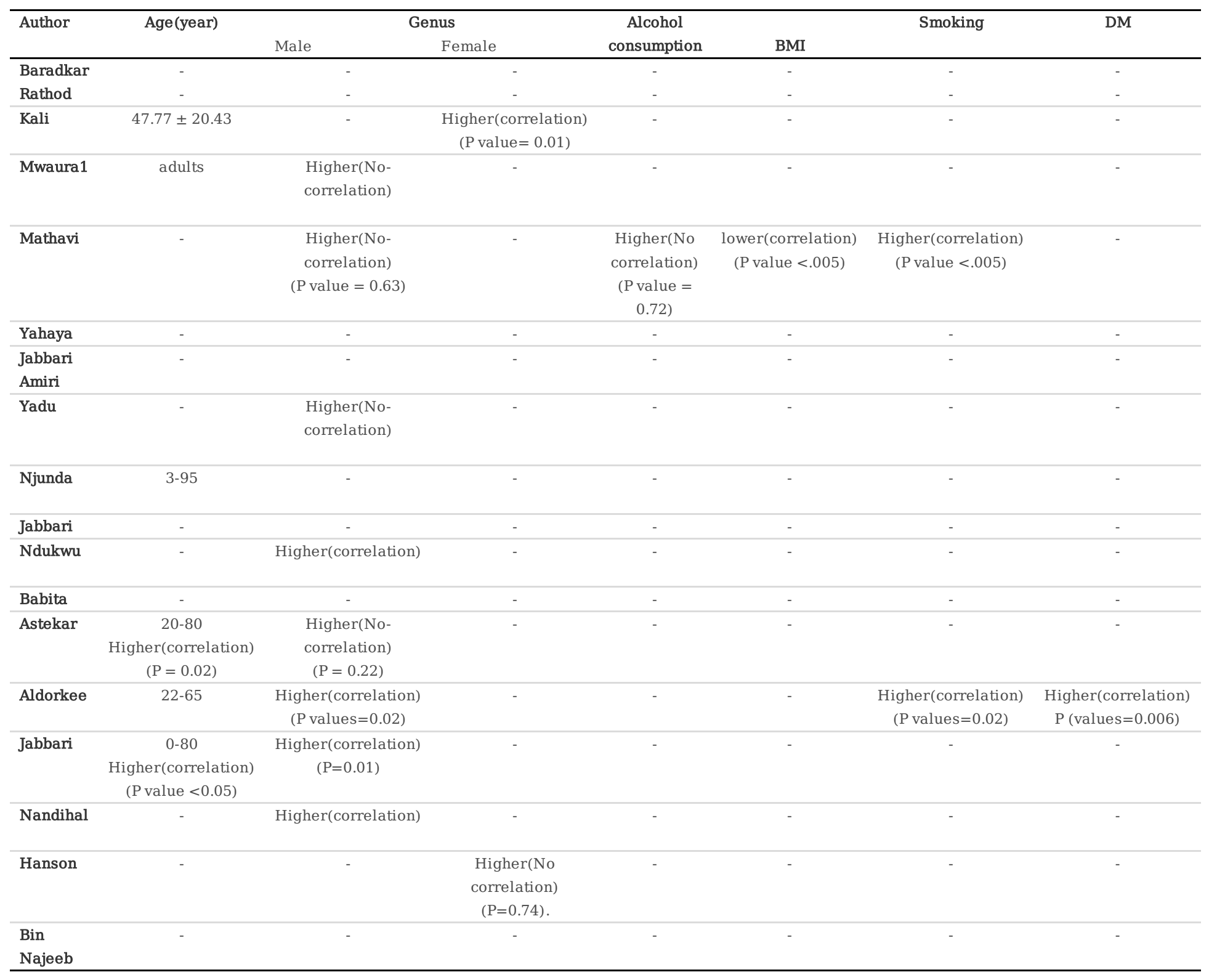

\section{Figures}




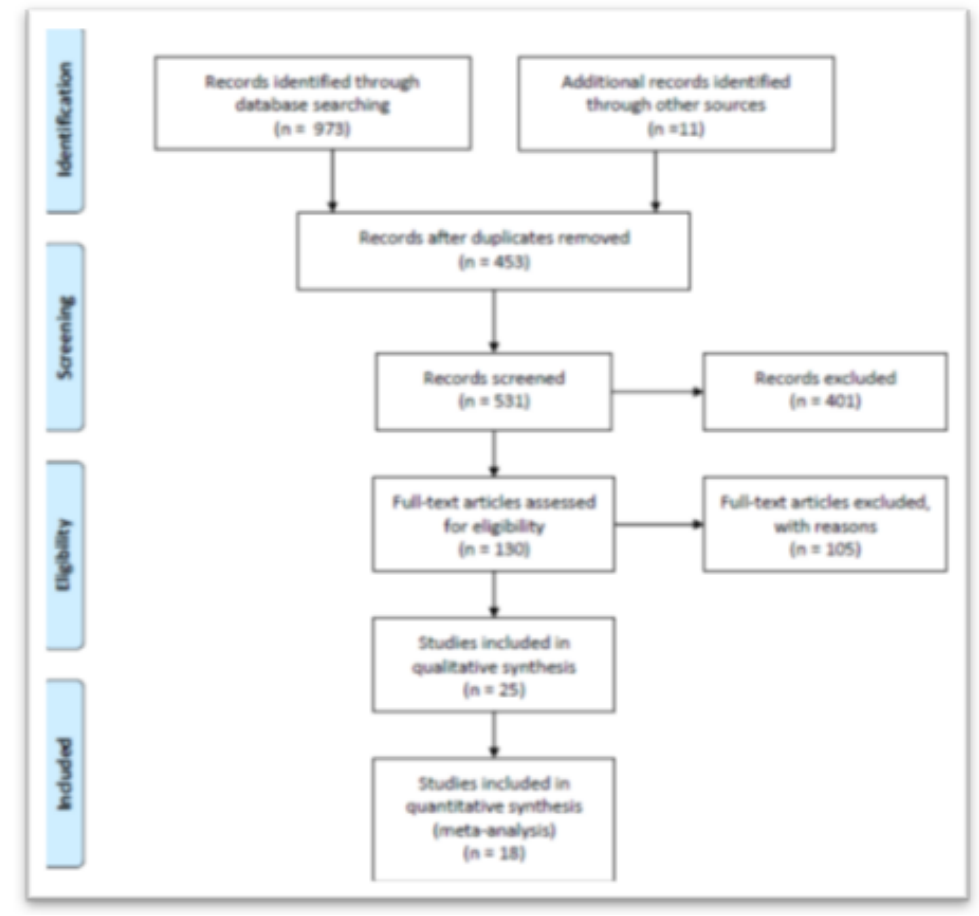

Figure 1

Flow diagram of selection process of included studies

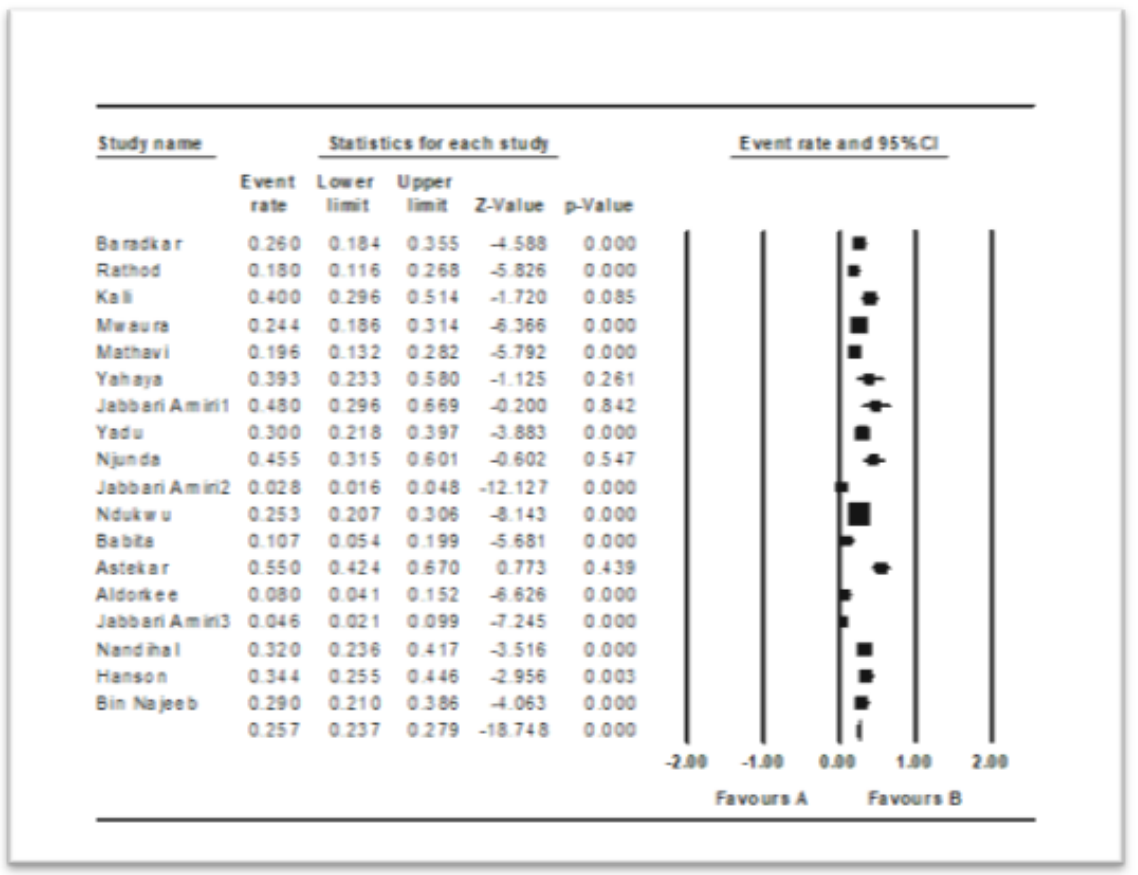

Figure 2

The Forest plot of the meta-analysis of the prevalence of Candida coinfection among patients with pulmonary tuberculosis 


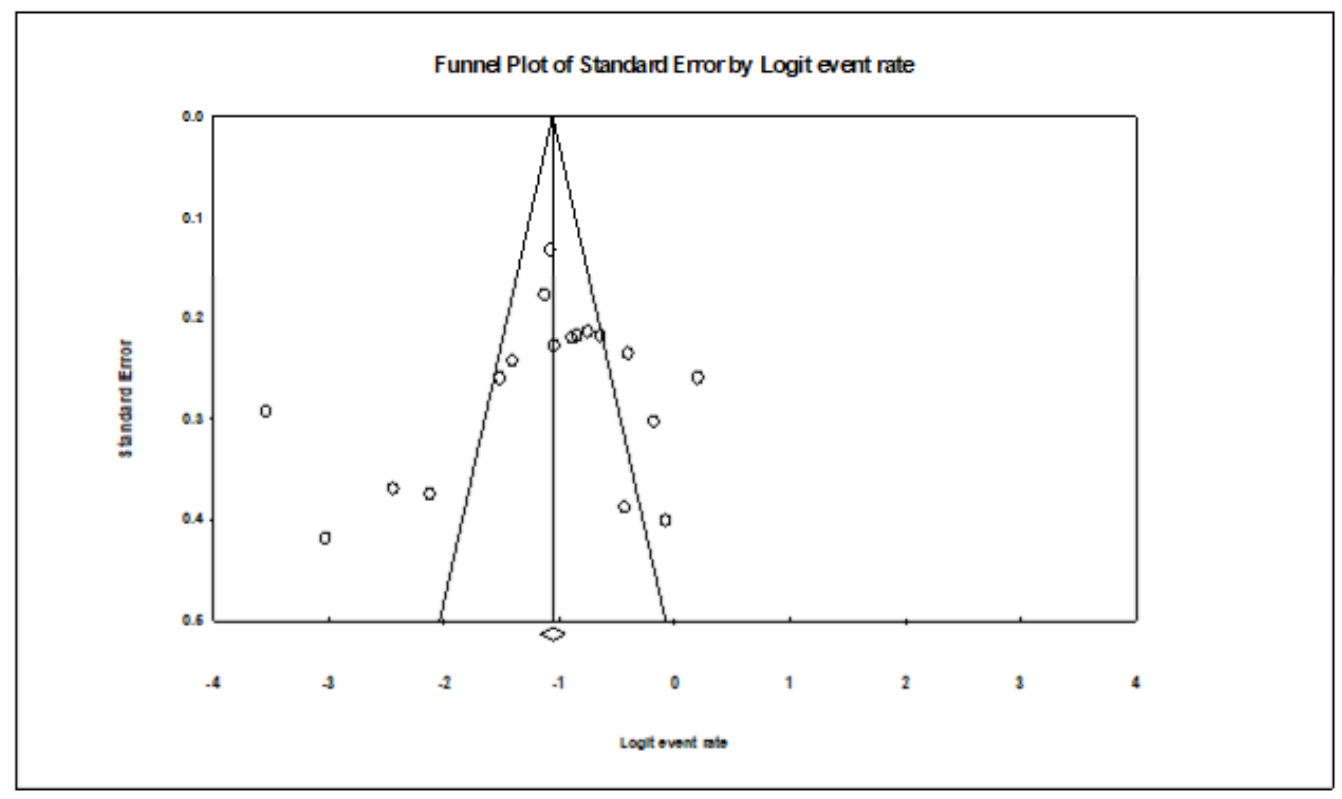

Figure 3

Funnel plot of meta-analysis on the prevalence of Candida coinfection in patients suffering from pulmonary tuberculosis

\section{Supplementary Files}

This is a list of supplementary files associated with this preprint. Click to download.

- PRISMA2009ChecklistFile1.pdf

- Qualityassesment.file2.pdf 